\title{
Demonstration of Local Protein Synthesis within Dendrites Using a New Cell Culture System That Permits the Isolation of Living Axons and Dendrites from Their Cell Bodies
}

\author{
Enrique R. Torre and Oswald Steward \\ Department of Neuroscience, University of Virginia Health Science Center, Charlottesville, Virginia 22908
}

The presence of polyribosomes within dendrites suggests a capability for local dendritic protein synthesis. However, local synthesis is difficult to evaluate because of rapid somatodendritic protein transport. The present study describes a two-surfaced culture system that allowed the separation of living axons and dendrites from their cell bodies of origin. Because this system eliminates the transport of proteins produced in the cell body, it was possible to study the extent of dendritic protein synthesis directly. Hippocampal neurons were plated on a Nucleopore polycarbonate membrane that was mounted on a thick matrix of proteins (Matrigel) fixed on a coverslip. As the neurons grew, axons and dendrites grew through the membrane into the Matrigel.

To evaluate local protein synthesis within dendrites, the membrane with the cell bodies was removed, leaving a dense array of transected dendrites and axons on the coverslip with few contaminant cell bodies. Absence of cell bodies was confirmed by staining with the nuclear stain Hoechst 33258. Coverslips with isolated neurites were pulse labeled with ${ }^{3} \mathrm{H}$-leucine for $\mathbf{3 0} \mathrm{min}$, and fixed for autoradiography to identify sites of protein synthesis. Autoradiographic analyses revealed that isolated dendrites (immunochemically identified using antibodies against MAP2) became heavily labeled, whereas axons exhibited little if any labeling. The labeling was essentially eliminated when the neurites were pulse labeled with ${ }^{3} \mathrm{H}$-leucine in the presence of puromycin, whereas labeling was affected only minimally by chloramphenicol. The puromycin-sensitive incorporation of ${ }^{3} \mathrm{H}-\mathrm{leu}$ cine in dendrites demonstrates that the polyribosomes previously described are active in protein synthesis. This system will allow a characterization of synthetic activity within isolated neurites and provide a new approach to identifying proteins that are produced within dendrites.

In nerve cells, protein synthesis has until recently been assumed to be confined to the cell body. However, several lines of evidence now suggest that protein synthesis may also occur within dendrites in areas closely associated with the synaptic complex. It has long been known that dendrites, unlike axons, do contain

\footnotetext{
Received July 23, 1991; revised Sept. 25, 1991; accepted Oct. 3, 1991.

We are grateful to Drs. G. A. Banker and C. Dotti for helpful discussions and criticism during the development of the culture technique. This study was supported by a National Institutes of Health grant, NS 12333 to O.S.

Correspondence should be addressed to Oswald Steward, Department of Neuroscience, University of Virginia Health Science Center, Box 230, Charlottesville, VA 22908 .

Copyright (C) 1992 Society for Neuroscience $0270-6474 / 92 / 120762-11 \$ 05.00 / 0$
}

polyribosomes. However, it was the recognition that polyribosomes were preferentially localized beneath synapses (Steward and Levy, 1982) that provided the impetus for a more extensive analysis. It was demonstrated that during the time of synapse formation in early development (Steward and Falk, 1986) or synapse replacement following lesions (Steward, 1983) the number and localization of the polyribosomes were altered. Moreover, a system for the selective transport of RNA into dendrites has been characterized (Davis et al., 1987, 1990). More recent studies have revealed a selective localization of particular mRNAs within dendrites (Garner et al., 1988; Bruckenstein et al., 1990; Kleiman et al., 1990). Included among the mRNAs that are present in dendrites are the mRNAs for MAP2, a protein that is selectively distributed in neuronal cell bodies and dendrites but largely excluded from axons (Cáceres et al., 1984; Matus, 1988), and the mRNA for the $\alpha$-subunit of the calcium/calmodulin-dependent protein kinase II (CaM-kinase II) (Burgin et al., 1990), which is a major constituent of type I (asymmetric) postsynaptic membrane specializations (Kennedy et al., 1983; Kelly et al., 1984). However, most other mRNAs are restricted to the neuronal cell body. These data indicate a complex mechanism for mRNA sorting and transport within neurons.

Despite this evidence, it has not been definitely established whether the protein synthetic machinery in dendrites is active in protein synthesis. An active protein synthetic process is suggested by the dynamic changes in the polyribosomes during periods of growth (Steward, 1983; Steward and Falk, 1986), by the association between polyribosomes and elements of the cytoskeleton and membranous cisterns (Steward and Reeves, 1988), and by the steady turnover as indicated by the constant transport of recently synthesized RNA. Nevertheless, the results from experiments performed to document protein synthesis have been inconclusive. Pulse labeling of neurons in culture with ${ }^{3} \mathrm{H}-\mathrm{leu}-$ cine led to labeling throughout the dendritic arbor within minutes, which is consistent with local protein synthesis (Steward et al., 1988). However, a very rapid transport of newly synthesized proteins from the cell body could not be excluded. For these reasons, we sought to develop a way to evaluate protein synthesis within dendrites that had been completely separated from their cell bodies.

We chose a cell culture approach because it is possible to grow neurons under conditions in which they are physically isolated from other cell types. Thus, glial, epithelial, and blood cells that are common contaminants of tissue preparations can bc climinated. In addition, once dissociated neuronal cells have been established in culture, neurites can be transected but continue to live for a time (Shaw and Bray, 1977). This approach offers 
considerable advantages over subcellular fractionation techniques for studies of localized biochemical processes using autoradiography or other techniques that depend upon maintaining the local integrity of the neurites. However, isolating individual neurites by physical transection is not practical if the goal is to obtain large numbers of isolated neurites, as would be required for biochemical studies, or for isolation and characterization of the mRNAs present within dendrites. With these considerations in mind, we set about to develop a means to isolate dendrites in which the following concerns would be addressed: (1) the system should be simple, adding minimal time to the cell culture set up; (2) the system should permit rapid separation of neurites from their cell bodies; (3) the resulting material should be enriched in dendrites, with minimal contamination by other cell types or processes that may contain RNA-contamination by axons is not a concern because polyribosomes are essentially absent from the axons of neurons in culture; (4) finally, the dissection step must preserve the viability of the neurites, so that the protein synthetic machinery and other metabolic processes can be studied.

In the present article, we describe a new cell culture system that fulfills the above requirements. The strategy was to make a "double-surfaced coverslip." One of the surfaces (the plating surface) is porous and permits the passage of neurites but not cell bodies. The second surface, which receives the neurites, is attached to the plating surface by a protein matrix. After 10$15 \mathrm{~d}$ in vitro, the plating surface can be stripped off, leaving a nearly pure preparation of living axons and dendrites on the second surface.

This culture system was used to evaluate protein synthetic activity in dendrites. The strategy was similar to that used in other cell types to study the sites of protein synthesis. Isolated dendrites were pulse labeled with ${ }^{3} \mathrm{H}$-leucine, and the sites of protein synthesis were subsequently visualized by autoradiography. Our results reveal that isolated dendrites but not axons possess the capacity for protein synthesis. This system will make it possible to characterize further the protein synthetic machinery within dendrites and identify other local metabolic processes. Moreover, the ability to obtain relatively pure preparations of neuronal processes in which the only significant protein synthesis occurs in dendrites should make it possible to isolate the mRNAs present in dendrites, and clone the genes encoding messages that are selectively directed toward the dendritic compartment.

These results have been reported in abstract form (Torre and Steward, 1990).

\section{Materials and Methods}

\section{Design of the cell culture system}

The system used to isolate dendrites consisted of two different surfaces firmly bound to each other through a matrix of proteins and sealed all around with paraffin (Fig. 1).

The plating surface. The porous surface onto which neurons were plated was a Nucleopore polycarbonate filter (General Electric Co., Vallecitos Nuclear Center, Pleasanton, CA). This membrane was chosen because it has straight cylindrical channels of uniform size and because of its thickness (average of $10 \mu \mathrm{m}$ ) (Cornell, 1969; Wartiovaara et al., 1972, 1974). Since dendrites of neurons in culture grow to an average length of 200-300 $\mu \mathrm{m}$, both features of the membrane help to minimize the loss of material within the membrane. This membrane provides a solid support that is resistant to a wide range of chemicals and that has been used extensively for culturing different kinds of cells (Cornell, 1969; Nopanitaya et al., 1977; Caplan et al., 1986). Moreover, the thin Nucleopore filters are transparent, making it easy to visualize the cells and to evaluate the gross development of the culture. An additional advantage is that the membrane has very low background fluorescence, permitting immunostaining using fluorescent antibodies.

To determine a pore size that was large enough to permit the transit of neurites, but small enough to prevent the passage of cell bodies, we evaluated membranes with nominal pore diameters of $1,2,3,5$, and 8 $\mu \mathrm{m}$. Membranes were autoclaved and treated with poly-L-lysine (Sigma Chemical Co., St. Louis, MO; $1 \mathrm{mg} / \mathrm{ml}$ in $0.1 \mathrm{~m}$ borate buffer, $\mathrm{pH} \mathrm{8.3)}$ before being coupled with the second surface.

The second surface. This is the surface on which neurites grow after they have grown through the polycarbonate membrane. We used acidwashed coverslips treated with poly-L-lysine. The coverslips were bound to the Nucleopore membrane using Matrigel (Collaborative Research Co., Bedford, MA). Matrigel is an unfractionated extract of the Engelbreth-Holm-Swarm tumor that reconstitutes to a porous gel at $35^{\circ} \mathrm{C}$ (Kleinman et al., 1985). Matrigel contains laminin, collagen type IV, heparan sulfate, entactin, and nidogen (Kleinman et al., 1982), which support and stimulate neuritic growth (Chamak and Prochiantz, 1989; Chau et al., 1990). Thus, in addition to providing a three-dimensional matrix within which neurites can grow, the presence of extracellular matrix proteins may help to promote neurite elongation.

The Matrigel solution was diluted in minimum essential medium (MEM; GIBCO Laboratories; Grand Island, NY) and rat tail collagen solution (Sigma; $6: 3: 1$ ). When the sandwiches were prepared with Matrigel diluted by $50 \%$, the extent of neurite passage appeared greater. Higher dilutions produced a very weak matrix that dissolved after a few days in culture. Collagen was added to the diluted solution because this protein is one of the most important contributors to neuritic growth (Chamak and Prochiantz, 1989; Chau et al., 1990) and is present only in low concentrations in the Matrigel solution (Kleinman et al., 1982).

Assembling the system. An initial film of diluted Matrigel was applied to the glass coverslips and fixed by heating for $1 \mathrm{hr}$ at $70^{\circ} \mathrm{C}$. A second layer was then applied, over which the Nucleopore filter was positioned. Excess protein was extruded from the sandwich by pressing gently on the glass with forceps. The solution was allowed to gel and dry at room temperature. After drying, the membrane and the glass were firmly attached by the Matrigel. The borders of the sandwich were sealed with paraffin.

\section{Cell culture}

Cultures of hippocampal neurons were prepared as described by Bartlett and Banker (1984b). Briefly, rat fetuses were harvested from anesthetized female rats on the 18 th day of gestation. The hippocampi from 25-30 fetuses were dissected from the brains and treated with $0.25 \%$ trypsin for $15 \mathrm{~min}$ at $37^{\circ} \mathrm{C}$. The tissue was washed in $\mathrm{Mg} / \mathrm{Ca}$-free Hank's balanced salt solution (GIBCO), dissociated by repeated passage through a constricted Pasteur pipette, and filtered through a $70 \mu \mathrm{m}$ Nitex filter. A cell suspension of 1.0-1.5 $\times 10^{6}$ cells in 70-100 $\mu$ l of MEM containing $10 \%$ fetal bovine serum was plated on the Nucleopore surface of each sandwich. After $2 \mathrm{hr}$ at $36^{\circ} \mathrm{C}$, the cells attached, and the sandwiches were placed cell side down in dishes containing a confluent monolayer of astroglial cells. The sandwiches floated on the medium surface throughout the entire culture period. Cultures were maintained in MEMN2 medium of Bottenstein and Sato (1979), with $0.1 \%$ ovalbumin and $0.1 \mathrm{~mm}$ pyruvate. Cytosine arabinoside (Calbiochem, La Jolla, CA) (5 $\mu \mathrm{M})$ was added immediately after plating and again after $2 \mathrm{~d}$ in culture to inhibit glial proliferation.

\section{Identification of neuritic processes as axons or dendrites}

Previous studies have shown that dendrites of neurons in culture can be distinguished from axons by (1) their selective transport of recently synthesized RNA (Davis et al., 1987) and (2) their selective staining using antibodies against MAP2 (Cáceres et al., 1984, 1988). These two techniques were used to document that some of the neurites that grow through the Nucleopore membrane were dendrites.

${ }^{3} \mathrm{H}$-uridine labeling of dendrites. Cells on membranes were incubated for $1 \mathrm{hr}$ with ${ }^{3} \mathrm{H}$-uridine $(40 \mu \mathrm{Ci} / \mathrm{ml}$ of $\mathrm{MEM}$; specific activity, $37.5 \mathrm{Ci} /$ mmol; New England Nuclear, Boston, MA). The coverslips were then rinsed three times in MEM and returned to their original medium for $12 \mathrm{hr}$. Cold uridine ( $5 \mathrm{~mm}$ ) was added to the medium during the chase period. At the end of the $12 \mathrm{hr}$ incubation, the sandwiches were rinsed in Hank's balanced salt solution, the filter was peeled off, and the processes on the coverslips were fixed and processed for immunostaining and autoradiography (see below). 

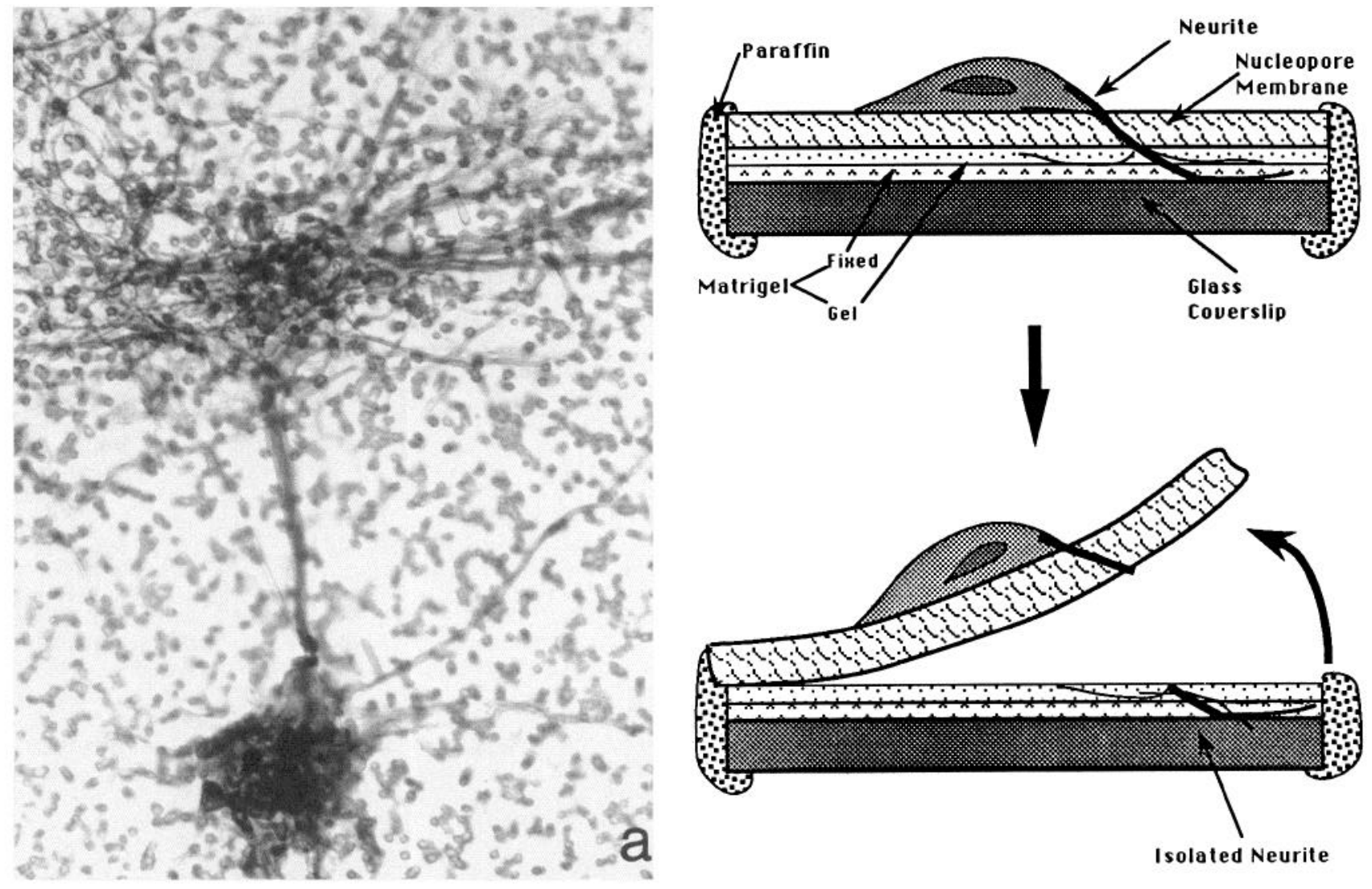

Isolated Neurite
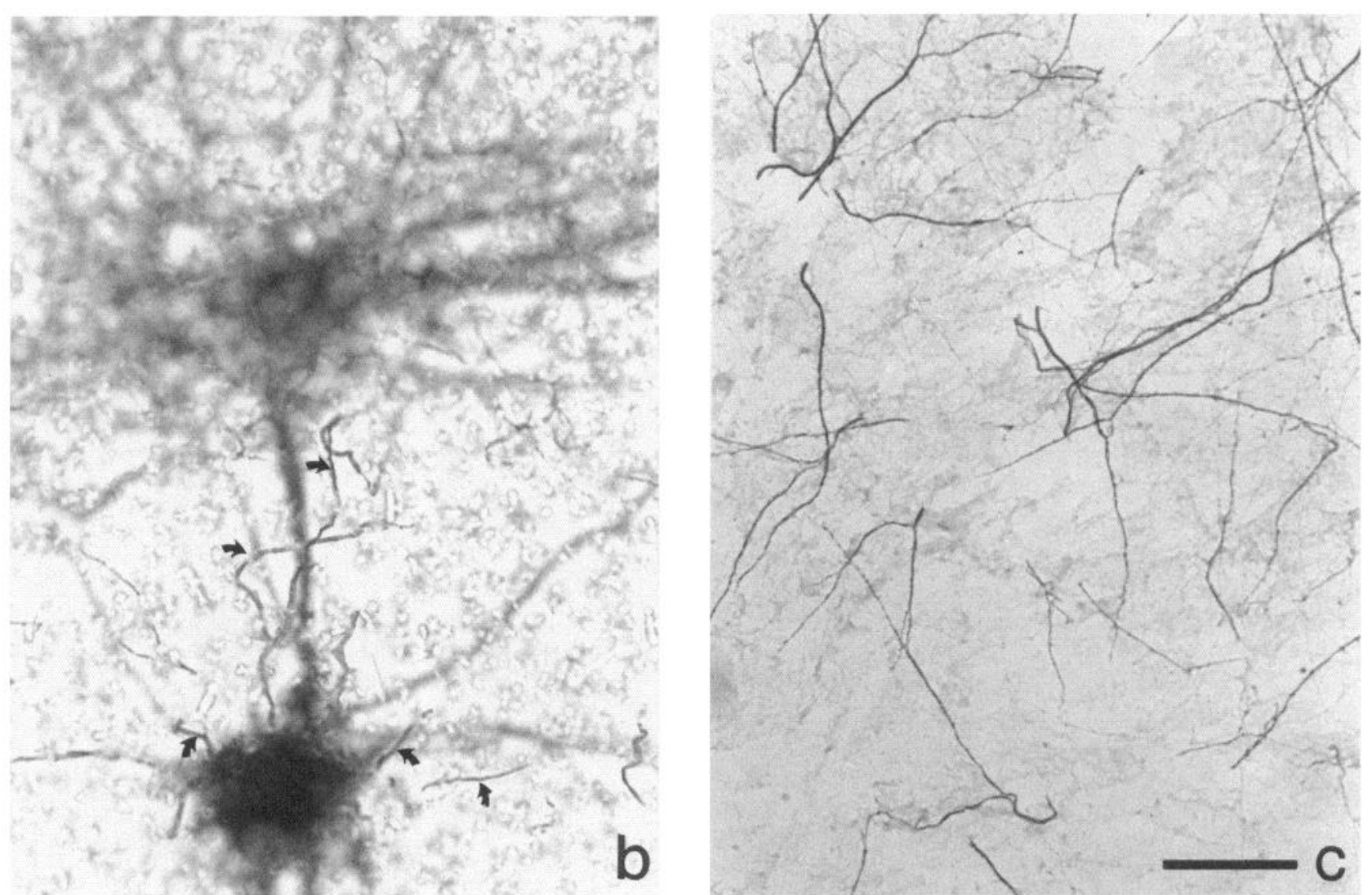

Figure 1. Cell culture system. The illustration in the upper right panel indicates the two surface culture technique. Acid-washed glass coverslips were treated with poly-L-lysine and then covered with a film of Matrigel that was fixed to the glass surface by heat treatment $\left(1 \mathrm{hr}\right.$ at $\left.70^{\circ} \mathrm{C}\right)$. A 
Immunohistochemistry. Coverslips were rinsed in $\mathrm{Mg} / \mathrm{Ca}$-free Hank's balanced salt solution and fixed in $4 \%$ paraformaldehyde $/ 0.25 \%$ glutaraldehyde in $0.1 \mathrm{~m}$ phosphate buffer ( $\mathrm{pH} 7.4$ ). After fixation, cells were permeabilized in graded ethanols and rehydrated in PBS. To reduce nonspecific binding of the primary antibodies, the coverslips were incubated for $30 \mathrm{~min}$ in PBS containing 10\% BSA and 1\% normal goat serum (Sigma). The coverslips were then incubated in one or more of the following primary antibodies for single or double immunofluorescence: (1) mouse monoclonal anti-MAP2 (AP14), 1:100; (2) mouse monoclonal anti-galactocerebroside, 1:100 [a gift from Dr. B. Ranscht (Ranscht et al., 1982); Friedrich-Miescher-Laboratorium, Max Planck, Tübingen, Germany]; (3) rabbit anti-sea urchin tubulin, 1:200 (Polyscience Inc., Warrington, PA); (4) rabbit anti-cow glial fibrillary acidic protein (GFAP), 1:100 (Accurate Chemical \& Scientific Corp., Westbury, NY); or (5) rabbit anti-myelin basic protein, 1:100 (Dako Corp., Santa Barbara, CA). The coverslips were incubated with the primary antibodies for $12 \mathrm{hr}$ at $4^{\circ} \mathrm{C}$, rinsed $3 \times(5 \mathrm{~min}$ each $)$ in PBS, and then incubated for $1 \mathrm{hr}$ with biotinylated goat anti-mouse IgG (1:50; Sigma) and/or fluorescein isothiocyanate (FITC)-labeled goat anti-rabbit IgG (1:200; HyClone Laboratories, Logan, UT). For the detection of biotinylated secondary antibodies, preparations were incubated for $30 \mathrm{~min}$ at room temperature with Extravidin labeled with peroxidase (1:50; Sigma) or with Texas red (1:500; Bethesda Research Laboratories, Gaithersburg, MD). Neurites were reacted for peroxidase in diaminobenzidine $/ \mathrm{H}_{2} \mathrm{O}_{2}$ as described elsewhere (Cáceres et al., 1984). The cultures were rinsed in PBS, dehydrated in graded ethanols, and cleared in xylene. Then, they were returned to $100 \%$ ethanol and air dried.

Histochemistry. After immunolabeling, coverslips were stained for 30 min with bisbenzimide (Hoechst 33258, Sigma; $1 \mu \mathrm{g}$ of bisbenzimide/ ml of PBS). At neutral pH, bisbenzimide selectively stains DNA, which is detected as blue fluorescence in UV (Hilwig and Grop, 1975). Thus, bisbenzimide staining reveals any cell bodies that were present on the Matrigel surface.

Autoradiography. Coverslips were dried and mounted cell side up on microscope slides. The slides were then coated with Kodak NTB2 emulsion (diluted 1:1 in water). After exposure for $7-10 \mathrm{~d}$ at $4^{\circ} \mathrm{C}$, the slides were developed in Kodak D- 19 at $15^{\circ} \mathrm{C}$, fixed, and coverslipped using Kaiser Glycerol jelly.

Visualization. Histological preparations were photographed using epifluorescence and dark-field illumination in order to localize silver grains over the stained processes.

\section{Local protein synthesis in dendrites}

To evaluate whether there was local synthesis of protein within dendrites, coverslips with isolated neurites were pulse labeled with ${ }^{3} \mathrm{H}$ leucine. Eukaryotic ribosomal and mitochondrial protein synthesis inhibitors were used to characterize the nature of the incorporation that was observed.

Pulse labeling with ${ }^{3} \mathrm{H}$-leucine. Sandwiches were preincubated for 6 $\mathrm{hr}$ in leucine-free MEM-N2 medium. Membranes were then peeled off, and the coverslips with the remaining neurites were incubated for 30 min at $37^{\circ} \mathrm{C}$ with $120 \mu \mathrm{Ci} / \mathrm{ml}$ of ${ }^{3} \mathrm{H}$-leucine $(60 \mathrm{Ci} / \mathrm{mmol}$, New England Nuclear) in the same medium. At the end of the incubation period, coverslips were rinsed in Hank's balanced salt solution containing 5 mM cold leucine, fixed with paraformaldehyde, and processed for immunostaining and autoradiography as described above.

Protein synthesis inhibitor experiments. Some preparations were incubated with ${ }^{3} \mathrm{H}$-labeled precursor as above in the presence of puromycin or chloramphenicol. Puromycin causes the premature release of nascent peptide chains in both eukaryotic and prokaryotic cells, thus inhibiting protein synthesis. Chloramphenicol inhibits peptide bond formation in prokaryotes and mitochondria (Vazquez, 1974). Puromycin $(100 \mu \mathrm{M})$ or chloramphenicol $(25 \mu \mathrm{g} / \mathrm{ml})$ was added $3 \mathrm{hr}$ before the pulse during the preincubation period. At the end of the preincubation, the filters were peeled off, and the coverslips were transferred to a medium containing the appropriate protein synthesis inhibitor along with $120 \mu \mathrm{Ci} / \mathrm{ml}$ of ${ }^{3} \mathrm{H}$-leucine for $30 \mathrm{~min}$. Controls were incubated in the same medium without inhibitors. The cultures were fixed and processed for immunochemistry and autoradiography as described above.

\section{Results}

\section{Filter setup}

In initial experiments, we evaluated the extent of cell attachment and neurite growth through Nucleopore membranes of different pore sizes. Cells were plated $\left(20,000 \mathrm{cells} / \mathrm{cm}^{2}\right)$ on single polyL-lysine-treated membranes. The membranes were coincubated with glia for 1,2 , or $5 \mathrm{~d}$, and the cells were then fixed and immunostained with a monoclonal antibody against MAP2. At each time point, individual neurons exhibited morphological characteristics typical of cultured hippocampal neurons according to the criteria of Dotti et al. (1988). That is, after $24 \mathrm{hr}$ in culture most neurons had short processes, roughly equal in length, that could not be identified as axons or dendrites (stage 2). Howcver, some ncurons posscsscd a single process that was many times longer than the others. Dotti et al. (1988) have shown that these processes become axons. Cells with a single process larger than others are said to be in stage 3. By $48 \mathrm{hr}$, every neuron was in stage 3 . By the fifth day in culture, the short processes exhibited dendritic morphology.

It was possible to detect processes growing through the pores to the opposite side of the membrane after $24 \mathrm{hr}$ in culture. By the fifth day in culture, the number of neurites growing on the side of the filter opposite to the cell bodies was substantial. The majority of the crossing processes appeared to arise from small groups of cells. Neurites from isolated cells grew for long distances on the membrane surface, avoiding the pores, even though the cell body was sometimes adjacent to a pore. These results suggested that the growth of neurites through the pores depended upon the amount of free surface available. With less free surface (i.c., grcater cell density), there appeared to be a greater probability that the neurites would grow through the pores.

To evaluate this prediction, cells were plated at different densities (from $5 \times 10^{4}$ to $1.5 \times 10^{6}$ cells per membrane). The very high-density culture was well supported by the Nucleopore membrane. By $2 \mathrm{hr}$ after plating, most cells had attached to the membrane, forming a homogeneous layer of cells. Within $2 \mathrm{~d}$, the cells were found in spherical aggregates of uniform size. By $5 \mathrm{~d}$, aggregates were interconnected with each other via neuritic bundles, creating a networklike structure (Fig. 1).

Qualitatively, the number of neurites in the Matrigel increased as cell density increased. Plating densities above $10^{6}$ cells per filter consistently resulted in high passage of neurites to the second surface. However, many cell bodies were also seen on the Matrigel surface under these circumstances. To determine the optimal pore size that would permit the passage of neurites but prevent the passage of cell bodies, ncurons wcrc cultured on membranes of different nominal pore diameters $(8,5,3,2$, and $1 \mu \mathrm{m}$ ). A large number of cells were seen on the Matrigel side of the membrane with nominal pore sizes of 8 or $5 \mu \mathrm{m}$ diameter. When membranes with $3 \mu \mathrm{m}$ pores were used, the number of cells on the Matrigel surface was never higher than

\footnotetext{
second layer $(\mathrm{Gel})$ was then applied over which a poly-L-lysine-treated Nucleopore polycarbonate membrane was mounted. The sandwich was air dried at $35^{\circ} \mathrm{C}$, and the borders were sealed with paraffin. From 1 to $1.5 \times 10^{6}$ cells per sandwich were plated on the membrane surface and cocultured with a confluent monolayer of glial cells. $a$ and $b$ illustrate a 15-d culture stained with MAP2/peroxidase in order to reveal cell aggregates and neurites: $a$, growing on the surface of the Nucleopore membranc; $b$, ncuritcs cmerging from the pores on the opposite site of the membrane (arrows); $c$, neurites that remain on the Matrigel surface after removing the Nucleopore membrane. Scale bar, $25 \mu \mathrm{m}$.
} 

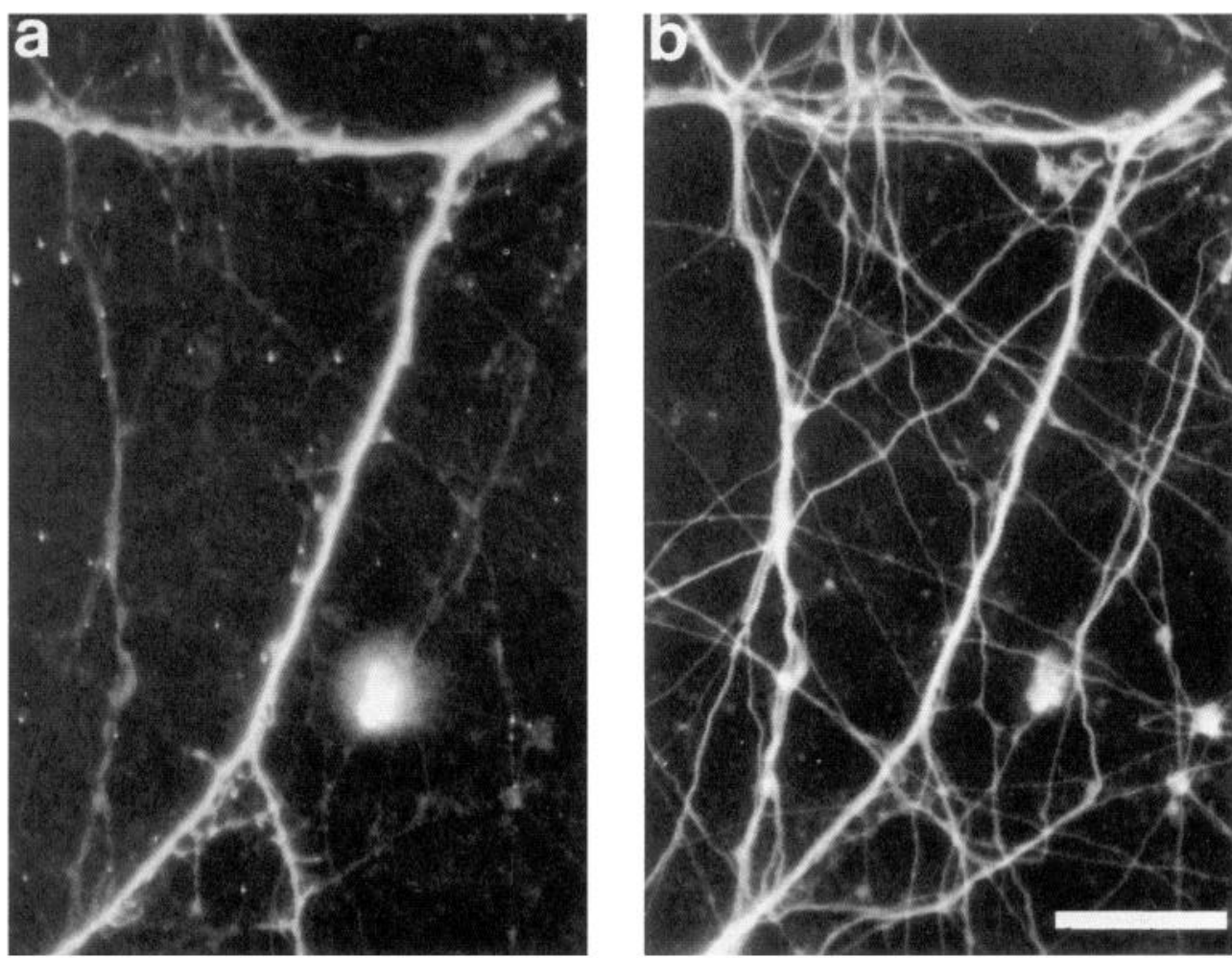

Figure 2. Characterization of neurites as dendrites or axons. Dendrites were identified by their selective staining for MAP2, and by the transport of recently synthesized RNA. Panels show isolated neurites on the Matrigel surface that were simultaneously stained for MAP2 (a) and tubulin $(b)$ as described in Materials and Methods; detection of bound antibodies was with goat anti-mouse biotin-Texas red-conjugated streptavidin and FITC-conjugated goat anti-rabbit antibodies, respectively. The absence of contaminant cell bodies was assessed by concurrent staining with bisbenzimide to visualize cell nuclei. In other experiments, cells were pulse labeled with ${ }^{3} \mathrm{H}$-uridine for $1 \mathrm{hr}$ and then incubated for $12 \mathrm{hr}$ in medium containing $5 \mathrm{~mm}$ cold uridine. At the end of the chase, the Nucleopore membrane was stripped off and the neurites on the Matrigel surface were fixed, stained for MAP2 and DNA (bisbenzimide), and exposed for autoradiography for $10 \mathrm{~d}$. $c$, MAP2-labeled dendrites on the Matrigel surface; $d$, pattern of labeling with ${ }^{3} \mathrm{H}$-uridine. Scale bars, $25 \mu \mathrm{m}$.
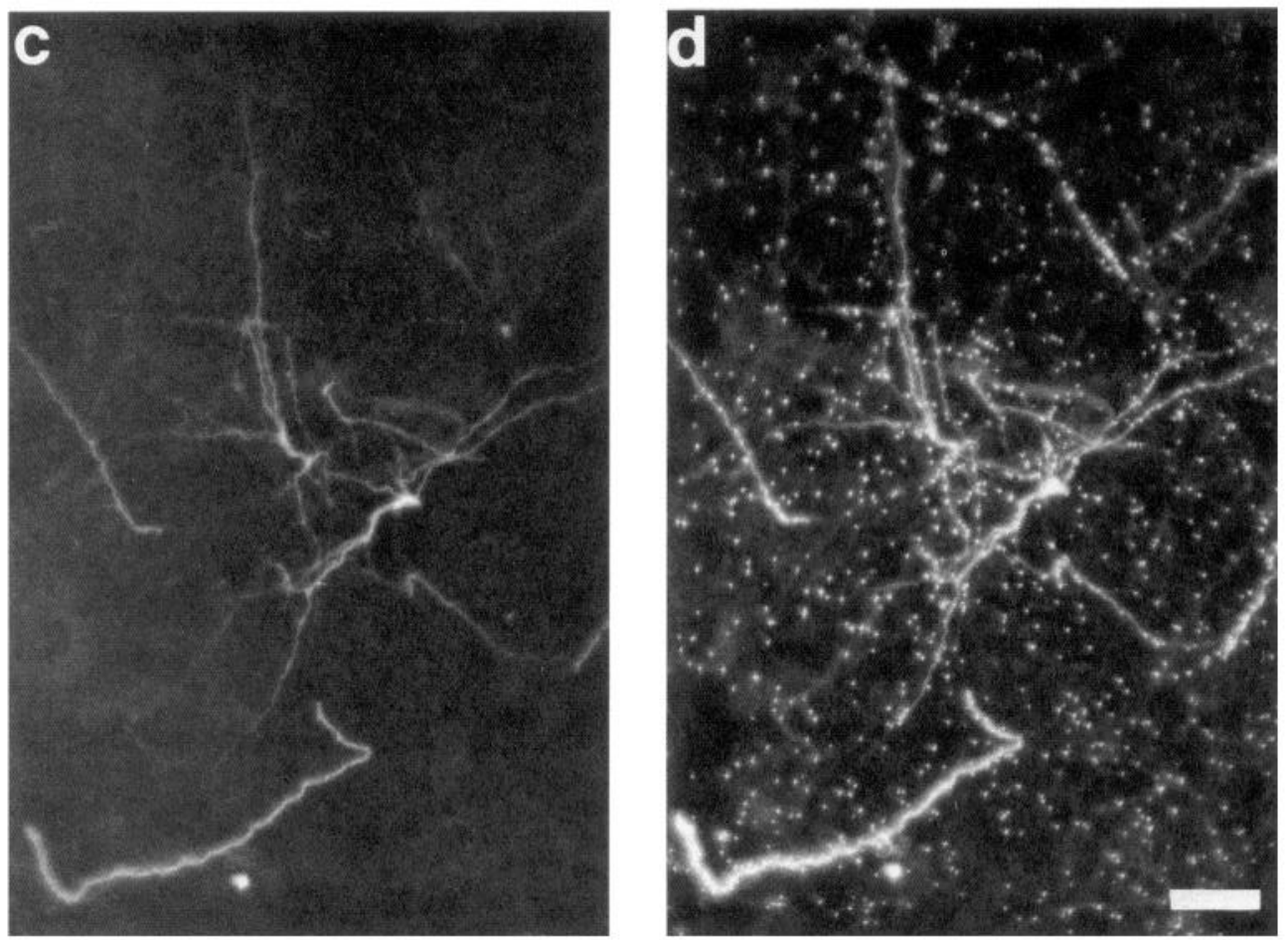

10. Neurons and glial cells were eliminated from the Matrigel surface when membranes with 2 and $1 \mu \mathrm{m}$ pore diameters were used. However, some macrophages were seen, particularly with membranes of $2 \mu \mathrm{m}$ pore diameter. This may be due to the fact that some pores overlap (Wartiovaara et al., 1974), producing a pore larger than the nominal size. The largest number of neurites were found when the $3-\mu \mathrm{m}$-pore membranes were used.
There were also frequent neuritic bundles. With 1 or $2 \mu \mathrm{m}$ pore diameters, the yields of neurites were somewhat lower but cleaner; that is, axonal bundles were seldom seen and cell contamination was usually negligible. However, neuritic passage was reduced. One possibility that could account for the difference between membranes with different pore sizes is that the Matrigel may need to enter the pores in order to facilitate the neuritic 
penetration. Thus, pore diameters of 2 and $1 \mu \mathrm{m}$ should produce a higher resistance to the Matrigel solution. In support of this possibility, it was found that neurite passage was greater when the membranes were moistened just before applying them to the Matrigel.

An acceptable compromise between contamination by cell bodies and neuritic yield on the Matrigel surface was obtained by using membranes with a nominal pore diameter of $3 \mu \mathrm{m}$. These conditions were acceptable for the present studies because the presence of a few cell bodies on the second surface did not compromise the interpretation of the autoradiographic analysis of dendrites that have been separated from their cell bodies (because the cell bodies could be detected using bisbenzimide). Thus, these conditions were used for the subsequent experiments described in this report.

\section{Identification of dendrites}

The goal in developing this culture system was to isolate living dendrites from their cell bodies. Thus, it was important to document the identity of the neuritic processes. We adopted the following criteria for identifying dendrites. To be considered a dendrite a neurite should (1) exhibit the morphological features of dendrites (tapering with distance from the cell body, and at each branch point), (2) stain positively for MAP2 and tubulin (Cáceres et al., 1986), and (3) show transport of recently synthesized RNA after pulse labeling with ${ }^{3} \mathrm{H}$-uridine (Davis et al., 1987). By contrast, axons should be more uniform in diameter, be longer than dendrites and less branched, be MAP2 negative, and show only minimal if any labeling after a ${ }^{3} \mathrm{H}$-uridine pulse (Davis et al., 1987; Banker and Waxman, 1988). Glial processes sometimes may show an overall morphology similar to dendrites, and are heavily labeled after a pulse with ${ }^{3} \mathrm{H}$-uridine (L. Davis, G. A. Banker, and O. Steward, unpublished observations). However, glial processes can be distinguished from dendrites because they stain positively for GFAP (in the case of astrocytes), or myelin basic protein and galactocerebrosides (in the case of oligodendrocytes) (Ranscht et al., 1982). In addition, glia do not stain for MAP2.

Based on these criteria, there were substantial numbers of axons and dendrites in each preparation, although the axon: dendrite ratio was variable. Many of the processes stained positively for MAP2 and tubulin and had the morphology characteristic of dendrites (Fig. 2). It was sometimes possible to visualize spinelike structures along the surface of MAP2-stained processes. When neurites were separated from their cell bodies of origin $12 \mathrm{hr}$ after a pulse with ${ }^{3} \mathrm{H}$-uridine, silver grains were present almost exclusively over MAP2-stained processes (Fig. 2). The grain density over these dendrites was generally comparable to the density observed in more distal portions of dendrites in intact neurons incubated under similar conditions (data not shown). The absence of Hoechst 33258-positive nuclear staining in continuity with the labeled dendrites confirmed that the vast majority of the identified dendrites on the coverslip were separated from cell bodies that remained on the membrane.

While some MAP2-stained processes were labeled, many were not. The reason for the lack of labeling is not clear. It is important to recall that the membranes were not removed until after the pulse and $12 \mathrm{hr}$ chase. Thus dendrites remained attached to their cell bodies during the pulse and chase. It is possible that not all dendrites of an individual neuron transport recently synthesized RNA. Alternatively, some of the neurons
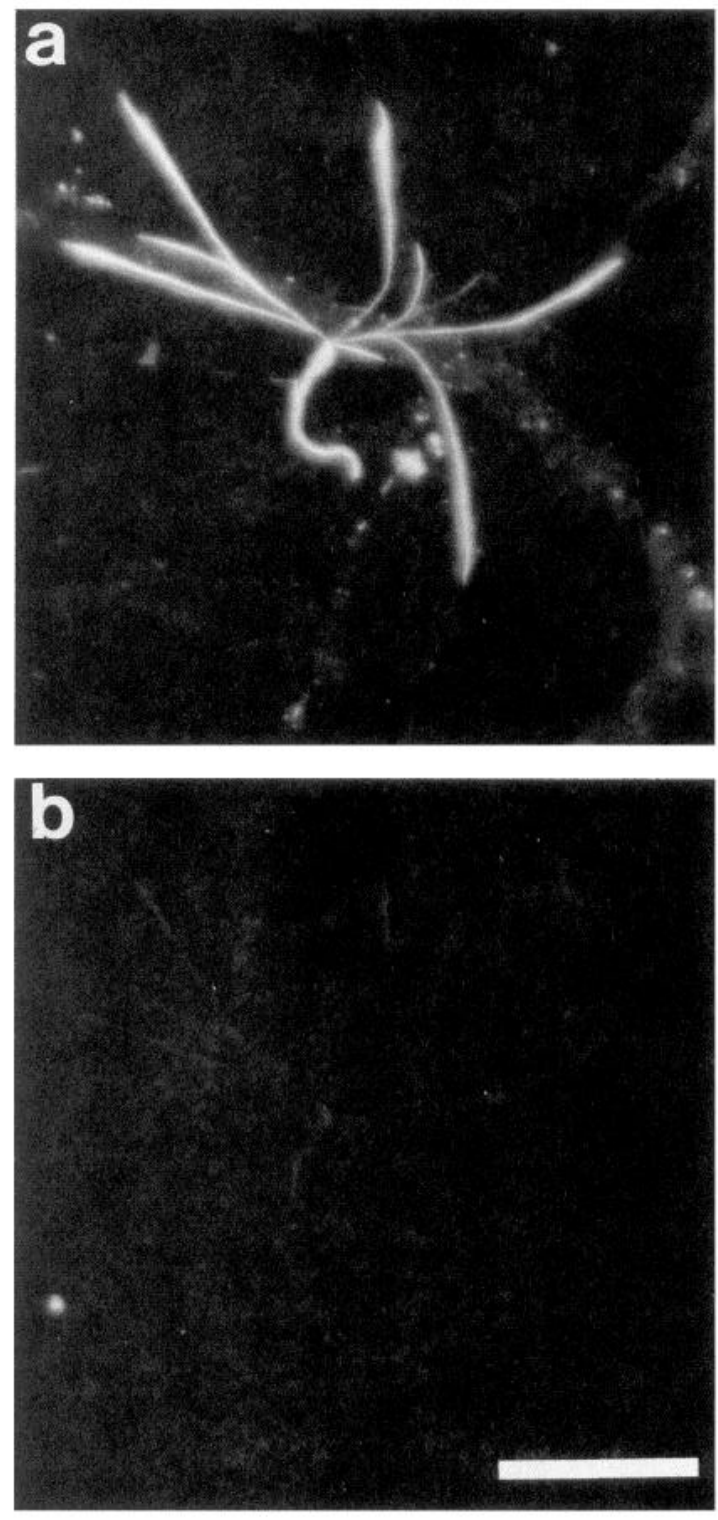

Figure 3. Identification of astroglial processes. The presence of astroglial processes on the Matrigel surface was evaluated by GFAP immunofluorescence. After $15 \mathrm{~d}$ in culture, the Nucleopore membrane was removed, and the coverslips were double stained for GFAP and MAP2 as described in Materials and Methods. Detection of bound antibodies was with goat anti-rabbit biotin-Texas red-conjugated streptavidin and FITC-conjugated goat anti-mouse antibodies, respectively. A few GFAPpositive profiles were detected in some preparations $(a)$. These were MAP2 negative $(b)$. Scale bar, $25 \mu \mathrm{m}$.

on the membrane may not be viable or actively synthesizing RNA. It may also be that the dendrites lay too deep in the Matrigel to expose the emulsion in the case of low-energy ${ }^{3} \mathrm{H}$ labeled molecules, or that there was some technical artifact in the combined autoradiographic/immunofluorescent preparations that interfered with grain development.

As expected, most of the thin processes that resembled axons stained positively for tubulin but did not stain for MAP2. After ${ }^{3} \mathrm{H}$-uridine labeling, these putative axons were usually unlabeled, although some showed a few scattered silver grains (Fig. 2).

Isolated glial processes did not seem to be a major contam- 

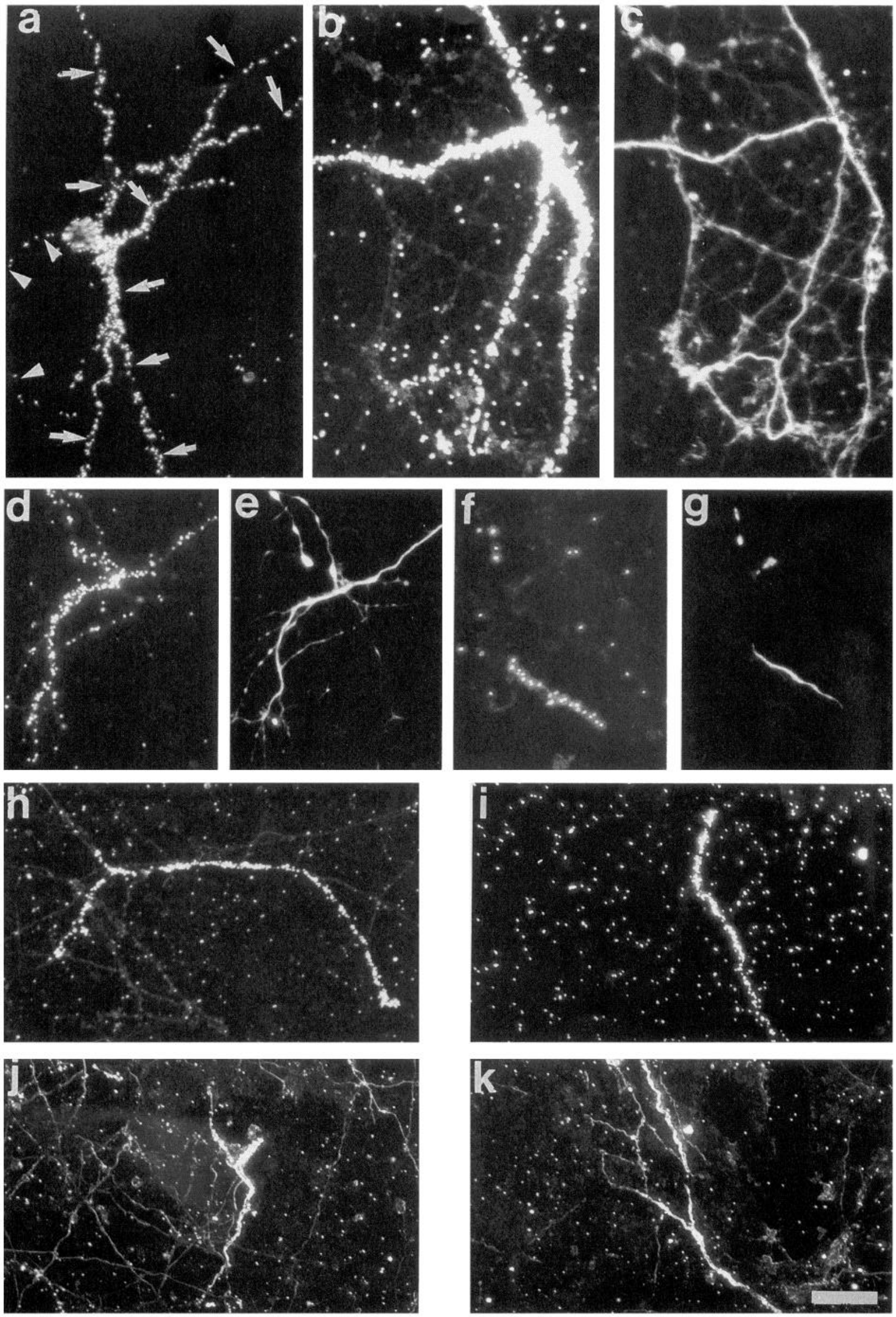
inant in our preparations. Double immunostaining experiments revealed the presence of a few GFAP-positive astroglial processes in some preparations. Glial processes were easily distinguished from dendrites because of their particular morphology (smoother, short, and with wider tips) and MAP2-negative staining (Fig. 3). Glial processes were more apparent in the preparations where cells and axonal bundles on the Matrigel surface were abundant. Although we do not have a good explanation for the increased passage of axon and glial processes in some preparations, changes in the properties of some of the Matrigel constituents after a long storage cannot be ruled out. Immunostaining for GFAP was not done for the pulse-labeling experiments. However, the absence of labeled processes with the characteristics described for glial processes indicates that they did not reach the Matrigel surface of those preparations.

No myelin basic protein- or galactocerebroside-positive profiles were observed when the cultures were immunostained with these oligodendroglial markers (data not shown).

\section{Dendritic protein synthesis}

For the studies of dendritic protein synthesis, we used membranes with $3 \mu \mathrm{m}$ pore diameter, because they constitute the best compromise between high neurite yields and low amounts of cell body contamination. The stringent control provided by the colocalization of silver grains over MAP2-stained processes, plus the absence of nuclear staining with bisbenzimide in the vicinity of labeled dendrites, assured a strict interpretation of the results even when a few cells were present on the Matrigel surface. Dendrites were separated from the cell bodies and pulse labeled for $30 \mathrm{~min}$ with ${ }^{3} \mathrm{H}$-leucine. Then, they were fixed and treated for immunochemistry and autoradiography as described in Materials and Methods.

As illustrated in Figure 4, after a short pulse with ${ }^{3} \mathrm{H}$-leucine many isolated dendrites became labeled. Labeling was often heavy from the cut end to the dendritic tip (Fig. $4 b$ ), resembling dendrites cut at their bases (see Fig. $4 a$ ). Most of the shorter and thinner MAP2-stained processes exhibited a less homogeneous and patchy labeling (Fig. $4 d, f$ ) as if they were cut more distally.

One possibility that could account for the labeling is incorporation of the precursor within dendritic mitochondria. These organelles can actively incorporate radioactive amino acids into proteins (McLean et al., 1958; Bhat et al., 1982), and they are found throughout dendrites. Mitochondrial protein synthesis, however, can be distinguished from cytoplasmic protein synthesis by its sensitivity to chloramphenicol (Vazquez, 1974; Bhat et al., 1982). Thus, isolated neurites were incubated with ${ }^{3} \mathrm{H}$-leucine in the presence of chloramphenicol. As illustrated in Figure $4, h$ and $i$, the extent of dendritic labeling was reduced only slightly by chloramphenicol. On the other hand, when isolated dendrites were incubated with ${ }^{3} \mathrm{H}$-leucine in the presence of puromycin, dendritic labeling was virtually eliminated (Fig. $4 j, k)$. Many dendrites were completely unlabeled. Nevertheless, because unlabeled dendrites are also common in the control, we cannot determine whether labeling in any individual dendrite was inhibited by the puromycin, or whether that particular dendrite was damaged as a consequence of the cut. Nevertheless, the total absence of incorporation in the presence of puromycin and the lack of effect of chloramphenicol indicate that the dendritic protein synthesis is predominantly eukaryotic.

Individual axons were generally unlabeled or showed only a few scattered silver grains after incubation with ${ }^{3} \mathrm{H}$-leucine. Densely packed axonal bundles showed somewhat more labeling. However, axonal labeling was not evident in preparations treated with chloramphenicol, suggesting that protein synthesis in axons may be of mitochondrial origin. There were no noticeable changes in the pattern of labeling with longer autoradiographic exposures, although the density of labeling did increase. Although we did not stain for GFAP in the experiments involving pulse labeling with ${ }^{3} \mathrm{H}$-leucine, we could not detect MAP2-negative processes with the morphological characteristics of glial processes that were labeled with ${ }^{3} \mathrm{H}$-leucine.

\section{Discussion}

Previous studies from our laboratory have led to the hypothesis that polyribosomes beneath synapses form part of an apparatus for the synthesis of particular proteins that play a role in constructing and maintaining synaptic specializations (Steward and Levy, 1982; Steward and Fass, 1983; Steward, 1986). Subsequent observations that supportcd this hypothesis included (1) the discovery of a selective transport of recently synthesized RNA into dendrites (Davis et al., 1987), (2) observations indicating that the number of dendritic polysomes is modified during periods of synapse construction (Steward, 1983; Steward and Falk, 1986; Steward and Ribak, 1986), (3) the discovery that certain mRNAs are localized in dendrites (Garner et al., 1988; Bruckenstein et al., 1990; Burgin et al., 1990; Kleiman et al., 1990), and (4) the discovery that some proteins that become part of the synaptic junction are synthesized within synaptosomes (Rao and Steward, 1991; Steward et al., in press). However, none of these studies could document the extent to which the putative protein synthetic machinery was active in synthesizing proteins.

The assessment of local protein synthesis within dendrites required that we overcome some unique problems. Because dendritcs extend only a few hundred micrometers from their cell bodies (Bartlett and Banker, 1984b; Banker and Waxman, 1988), it is very difficult to separate intact dendrites by subcellular fractionation from tissues or cell cultures. Studies using subcellular fractions such as synaptosomes require elaborate controls to assess the contribution of contaminating elements (cell body fragments and glia; see Rao and Steward, 1991). In

\footnotetext{
Figure 4. Local synthesis of proteins within dendrites. After $12 \mathrm{~d}$ in culture, three groups of sandwiches were randomly selected and preincubated for $6 \mathrm{hr}$ in leucine-free MEM-N2 medium. Puromycin $(100 \mu \mathrm{M})$ or chloramphenicol $(25 \mu \mathrm{g} / \mathrm{ml})$ was added $3 \mathrm{hr}$ before the pulse to two of the groups. At the end of the preincubation, the Nucleopore membrane was removed, and the isolated neurites were incubated in MEM-N2 medium with ${ }^{3} \mathrm{H}$-leu for $30 \mathrm{~min}$. Coverslips were washed, fixed with paraformaldehyde, stained for MAP2 and DNA, and exposed for autoradiography for $10 \mathrm{~d}$. Dark-field and fluorescence observation revealed labeling over isolated neurites $(b, d$, and $f)$ that stained positively for MAP2 $(c, e$, and $g$ ). The extent of labeling was comparable to the label observed over dendrites of intact neurons present on the Matrigel surface $(a$, arrows). Newly synthesized proteins were transported in axons of intact cells $(a$, arrowheads), but there was little or no labeling over isolated axons that had been incubated with ${ }^{3} \mathrm{II}$-leucine $(b)$. Chloramphenicol did not significantly affect ${ }^{3} \mathrm{H}$-leucine incorporation within dendrites $(h$ and $i)$, while puromycin virtually eliminated the labeling ( $j$ and $k$ ). Scale bar, $25 \mu \mathrm{m}$.
} 
addition, it is likely that proteins that are translated within dendrites are also synthesized in the cell body (i.e., MAP2) and, conversely, that most of the dendritic proteins that are not locally synthesized arc supplied by somatodendritic transport. Thus, this situation may lead to a complete overlap of the products of the synthetic machinery, making it difficult to interpret pulse-chase experiments or other biochemical analysis of the products of this machinery in intact cells (see Steward et al., in press). In addition, the characteristics of the somatodendritic transport of proteins are totally unknown. Thus, it was necessary to develop a means to isolate dendrites physically from their cell bodies.

The double-surfaced culture that we describe in this report allows physical isolation of living dendrites from their cell bodies, and direct visualization of the isolated processes. The system is simple to set up, and a good harvest of dendrites is easy to obtain. Neurons can be cultured on the Nucleopore membrane using the same standard conditions developed for low-density cultures on glass coverslips. The neurites growing in the Matrigel can be isolated from thcir ccll bodies in a single step. Dendrites, identified by morphological, immunochemical, and biochemical criteria (i.e., MAP2-positive staining, RNA transport), are abundant on the Matrigel surface. Many of the dendrites remained metabolically active after separation from their cell bodies, as evidenced by their protein synthetic activity. Although some of the cut processes may not have been metabolically active, a sufficient number were, so that it should be possible to characterize further the metabolic activity of the dendrites that survive.

By selecting membranes of different nominal pore diameters, it was possible to obtain preparations that were suitable for different types of studies. Thus, the use of membranes with 1 or $2 \mu \mathrm{m}$ pore diameters allowed the harvest of considerable numbers of dendrites with little if any contamination by cell bodies. These preparations will be useful for biochemical analyses of substrates and products of dendritic biosynthetic processes. On the other hand, 3- $\mu \mathrm{m}$-pore membranes render preparations with a larger number of dendrites and with only a slightly greater contamination by cell bodies. The system with 3 - $\mu \mathrm{m}$-pore membranes was useful for the autoradiographic evaluation of dendritic protein synthesis, since it was possible to confirm visually that a given dendrite was separated from its cell body of origin.

Using these preparations, we obtained evidence that constitutes the first direct confirmation of local synthesis of proteins within dendrites. Numerous dendrites showed labeling after incubation in ${ }^{3} \mathrm{H}$-leucine, and the labeling was eliminated when incubations were carried out in the presence of puromycin. Because the labeling was not affected by chloramphenicol, the incorporation is not likely to reflect protein synthesis by mitochondria.

Synthetic activity appeared to take place along the entire length of the dendrite, since the silver grains generally extended from the cut end to the dendritic tip. This observation is consistent with the electron microscopic evidence showing that, both in vivo (Steward and Levy, 1982) and in cultured neurons (Bartlett and Banker, 1984b), polyribosomes can be found distributed throughout dendrites. It is important to note, however, that transport might also account for the distribution of label in the isolated dendrites. The initial portion of dendrites has the same organelles (i.e., rough and smooth endoplasmic reticulum, Golgi, polysomes, mithochondria, etc.) present in the perikaryon.
For this reason, the initial segment of large dendrites is often considered as an extension of the cell body cytoplasm (Bartlett and Banker, 1984a; Banker and Waxman, 1988). Thus, if the dendrites collected on the coverslip surface were cut at their respective bases, it could be that ${ }^{3} \mathrm{H}$-leucine incorporation into proteins took place within the initial portion of the dendrite, with the material then being transported to the dendritic tips. Several lines of evidence led us to conclude that this is not the case, however. First, neurons on the membrane grew in aggregates. Thus, only the dendrites originating from neurons at the base of the aggregate and immediately adjacent to the pore would be close enough so that a proximal segment would extend through the pore. Since the average Nucleoporc mcmbrane thickness is around $10 \mu \mathrm{m}$, most initial segments would remain embedded in the membrane. In fact, on the basis of morphology and diameter, many of the MAP2-positive processes resembled terminal dendritic branches. Second, many dendrites showed labeling with a patchy distribution, and some thin dendrites labeled with ${ }^{3} \mathrm{H}$-leucine were small pieces that appeared to be distal segments that had been separated from the initial segment. These observations would be consistent with local synthesis throughout the proximodistal extent of the dendrite and would be inconsistent with the hypothesis that distal labeling resulted from transport from an initial segment.

Developmental studies in the hippocampus and studies of the reestablishment of synaptic contacts on denervated granule cells have suggested that the protein synthetic machinery within dendrites is regulated by the integrity of the synaptic complex. The number of polyribosomes is higher during periods of synaptic construction. Thus, this evidence supports the idea that this apparatus may be producing proteins that are crucial to the establishment or stabilization of the synaptic contact, or proteins that will determine the identity of the postsynaptic surface (i.e., neurotransmitter receptors, ion channels, etc.). Recent studies support this suggestion by revealing that some as yet unidentified protein constituents of synaptic junctions are locally synthesized (Rao and Steward, 1991; Steward et al., in press).

Of the two mRNAs that have been identified in dendrites to date, MAP2 is a cytoskeletal protein specifically localized in the somatodendritic domain (Cáceres et al., 1984), and the $\alpha$-subunit of CaM kinase II is a multifunctional kinase particularly enriched at the postsynaptic density. Interestingly, what these proteins have in common is their ability to interact with other proteins, modifying their biological properties. For example, MAP2 promotes microtubule formation by lowering the critical concentration of tubulin required for polymerization (Murphy and Borisy, 1975). Thus, one can speculate that the synthesis of MAP2 under synapses might provide a mechanism that would allow a local stabilization of microtubules, which in turn may promote local dendritic growth (Marek et al., 1980; Cáceres et al., 1988; Tucker et al., 1989). MAP2 has also been found in dendritic spines, in which there are many actin filaments but few microtubules (Morales and Fifkova, 1989). This is of interest because MAP2 can bind actin filaments in vitro, although with an affinity that is lower than that for microtubules (Seldon and Pollard, 1983; Sattilaro, 1986). In dendritic spines where there are usually no microtubules, and where the concentration of MAP2 may be regulated by local synthesis, actin may be more likely to interact with MAP2 (Matus, 1988; Morales and Fifkova, 1989).

CaM kinase II, on the other hand, can phosphorylate several 
proteins, including MAP2 (Schulman, 1984) and proteins of the postsynaptic density (Gurd, 1985). To date, little is known about how phosphorylation regulates these proteins. However, there is evidence that phosphorylation of MAP2 decreases the ability of MAP2 to bind microtubules (Murphy and Flavin, 1983) and actin filaments (Seldon and Pollard, 1983), and thus decreases cytoskeletal stability. Together, these findings suggest that local protein synthesis in dendrites may be able to induce substantial modifications of the postsynaptic microenvironment through changes in the production of a few proteins. This feature may provide a mechanism by which the morphology of an individual synaptic site or the efficacy of a particular synapse may be rapidly adjusted.

Posttranslational modifications of proteins (i.e., glycosylation, methylation, etc.), as well as targeting of proteins to the cellular membrane, require the transit of the molecules through the Golgi apparatus. Presently, there is no conclusive evidence that a Golgi-like organelle is present in dendrites. However, the system described in this article will give us the means to evaluate the presence of Golgi-like activity in isolated dendrites. If such activity is present within the dendritic compartment, it will certainly help to understand the local synthesis of some protein constituents of the postsynaptic specialization (Rao and Steward, 1991; Steward et al, in press). Moreover, it opens the interesting possibility that certain lipid components of the synaptic membrane may be locally produced. The localized synthesis of a subset of proteins and lipids within dendrites may form part of the mechanism of neuronal polarization, establishing protein/lipid microdomains that in turn contribute to the differentiation of dendritic morphology and function. Thus, the significance of the dendritic protein synthesis will be better understood when proteins that are locally synthesized have been identified, and when the signals that regulate their synthesis are known. The present study provides the means through which some of these questions can begin to be addressed. Answers to these questions will surely provide vital information for a better understanding of the structure and function of synapses throughout the life of the organism.

\section{References}

Banker GA, Waxman AB (1988) Hippocampal neurons generate natural shapes in cell culture. In: Intrinsic determinants of neuronal function (Lasek RJ, Black MM, eds), pp 61-82. New York: Liss.

Bartlett WP, Banker GA (1984a) An electron microscopic study of the development of axons and dendrites by hippocampal neurons in culture. I. Cells which develop without intercellular contacts. J Neurosci 4:1944-1953.

Bartlett WP, Banker GA (1984b) An electron microscopic study of the development of axons and dendrites by hippocampal neurons in culture. II. Synaptic relationships. J Neurosci 4:1954-1965.

Bhat N, Niranjan BG, Avadhani NG (1982) Qualitative and comparative nature of mitochondrial translation products in mammalian cells. Biochemistry 21:2452-2460.

Bottenstein JE, Sato GH (1979) Growth of a rat neuroblastoma cell line in serum-free supplemented medium. Proc Natl Acad Sci USA 76:514-519.

Bruckenstein DA, Lein PJ, Higgins D, Fremeau RT (1990) Distinct spatial localization of specific mRNAs in cultured sympathetic neurons. Neuron 10:809-819.

Burgin KE, Waxham MN, Rickling S, Westgate SA, Mobley WC, Kelly PT (1990) In situ hybridization histochemistry of $\mathrm{Ca}^{++} /$calmodulindependent protein kinase in developing rat brain. J Neurosci 10:17881798.

Cáceres A, Banker G, Steward O, Binder L, Payne M (1984) MAP2 is localized to the dendrites of hippocampal neurons which develop in culture. Dev Brain Res 13:314-318.

Cáceres A, Banker GA, Binder L (1986) Immunocytochemical local- ization of tubulin and microtubule-associated protein 2 during development of hippocampal neurons in culture. J Neurosci 6:714-722.

Cáceres A, Busciglio J, Ferreira A, Steward O (1988) An immunocytochemical and biochemical study of the microtubule associated protein MAP-2 during post-lesion dendritic remodeling in the central nervous system of adult rats. Mol Brain Res 3:233-246.

Caplan MJ, Anderson HC, Palade GE, Jamieson JD (1986) Intracellular sorting and polarized cell surface delivery of $\left(\mathrm{Na}^{+}, \mathrm{K}^{+}\right)$ATPase, and endogenous components of MDK cell basolateral plasma membranes. Cell Biol 46:623-631.

Chamak B, Prochiantz A (1989) Influence of extracellular matrix proteins on the expression of neuronal polarity. Development 106:483491.

Chau RMW, Zhao LP, Jen LS, Chan SO (1990) Factors affecting neurite outgrowth of occipital cortical explants. Cell Biol Int Rep 14: 143-153.

Cornell R (1969) The use of Nucleopore filters in ultrastructural studies of cell cultures. Exp Cell Res 56:156-158.

Davis L, Banker GA, Steward O (1987) Selective dendritic transport of RNA in hippocampal neurons in culture. Nature 330:447-479.

Davis L, Burger B, Banker GA, Steward O (1990) Dendritic transport: quantitative analysis of the time course of somatodendritic transport of recently synthesized RNA. J Neurosci 10:3056-3058.

Dotti CG, Sullivan CA, Banker G (1988) The establishment of polarity by hippocampal neurons in culture. J Neurosci 8:1454-1462.

Garner CC, Tucker RP, Matus A (1988) Selective localization of messenger RNA for cytoskeletal protein MAP 2 in dendrites. Nature 336: 674-677.

Gurd JW (1985) Phosphorylation of the postsynaptic density glycoprotein, gp 180 by $\mathrm{Ca}^{2+}$ calmodulin dependent protein kinase. J Neurochem 45:287-296.

Hilwig I, Grop A (1975) pH-Dependent fluorescence of DNA and RNA in cytologic staining with "Hoechst 33258." Exptl Cell Res 91: $457-460$.

Kelly PT, McGuinness T, Greengard P (1984) Evidence that the major postsynaptic density protein is a component of the $\mathrm{Ca}^{++}$calmodulindependent protein kinase. Proc Natl Acad Sci USA 81:945-949.

Kennedy MB, Bennet MK, Erondu NE (1983) Biochemical evidence that the major postsynaptic density protein is a subunit of a calmodulin-dependent protein kinase. Proc Natl Acad Sci USA 80:73577361.

Kleiman R, Banker GA, Steward O (1990) Differential subcellular localization of particular mRNAs in hippocampal neurons in culture. Neuron 5:821-830.

Kleinman HK, McGarvey ML, Liotta LA, Robey PG, Tryggvason K, Martin GR (1982) Isolation and characterization of type IV procollagen, laminin, and heparan sulfate proteoglycan from EHS sarcoma. Biochem 21:6188-6193.

Kleinman HK, McGarvey ML, Hassell JR, Star VL, Cannon FB, Laune GW, Martin GR (1985) Basement membrane complexes with biological activity. Biochem 25:312-318.

Marek A, Fellous A, Francon J, Nunez J (1980) Changes in composition and activity of microtubule-associated proteins during brain development. Nature 284:353-355.

Matus A (1988) Microtubule associated proteins: their potential role in determining neuronal morphology. Annu Rev Neurosci 11:29-44.

McLean J, Cohen G, Brandt I, Simpson M (1958) Incorporation of labeled amino acids into the protein of muscle and liver mitochondria. J Biol Chem 233:657-663.

Morales M, Fifkova E (1989) Distribution of MAP2 in dendritic spines and its colocalization with actin. Cell Tissue Res 256:447-456.

Murphy ASN, Flavin M (1983) Microtubule assembly using the microtubule-associated protein MAP-2 prepared in defined states of phosphorylation with protein kinase and phosphatase. Eur J Biochem 137:37-46.

Murphy RA, Borisy GG (1975) Association of high molecular weight protein with microtubules and their role in microtubule assembly in vitro. Proc Natl Acad Sci USA 72:2696-2700.

Nopanitaya W, Charlton RK, Turchin RL Jr, Grisham JW (1977) Ultrastructure of cells cultured on polycarbonate membranes. Stain Technol 52:143-149.

Ranscht B, Clapshaw PA, Price J, Noble M, Seifert W (1982) Development of oligodendrocytes and Schwann cells studied with a monoclonal antibody against galactocerebroside. Proc Natl Acad Sci USA 79:2709-2713. 
Rao A, Steward O (1991) Evidence that protein constituents of postsynaptic membrane specializations are locally synthesized: analysis of proteins synthesized in synaptosomes. J Neurosci 11:2881-2895.

Sattilaro W (1986) Interaction of microtubule-associated protein 2 with actin filaments. Biochemistry 25:2003-2009.

Schulman H (1984) Phosphorylation of microtubule-associated proteins by a $\mathrm{Ca}^{2+} /$ calmodulin dependent protein kinase. J Ccll Biol 99 11-19.

Seldon SC, Pollard TD (1983) Phosphorylation of microtubule-associated proteins regulates their interaction with actin filaments. $J$ Biol Chem 258:7064-7071.

Shaw G, Bray D (1977) Movement and extension of isolated growth cones. Exp Cell Res 104:55-62.

Steward O (1983) Alterations in polyribosomes associated with dendritic spines during the reinnervation of the dentate gyrus of the adult rat. J Neurosci 3:177-188.

Steward O (1986) Regulation of synaptogenesis through the local synthesis of protein at the postsynaptic site. In: Progress in brain research, vol 71 (Seil FJ, Herbert E, Carlson BM, eds), pp 267-279. Amsterdam: Elsevier.

Stcward O, Falk PM (1986) Protcin-synthetic machincry at postsynaptic sites during synaptogenesis: a quantitative study of the association between polyribosomes and developing synapses. J Neurosci 6 : $412-423$

Steward O, Fass B (1983) Polyribosomes associated with dendritic spines in the denervated dentate gyrus: evidence for local regulation of protein synthesis during reinnervation. In: Molecular and cellular interactions underlying higher brain functions (Changeux JP, Glowinski J, Imbert M, Bloom FE, eds), pp 131-136. Amsterdam: Elsevier.

Steward O, Levy WB (1982) Preferential localization of polyribosomes under the base of dendritic spines in granule cells of the dentate gyrus. J Neurosci 2:284-291.
Steward O, Reeves TM (1988) Protein synthetic machinery beneath postsynaptic sites on CNS neurons; association between polyribosomes and other organelles at the synaptic site. J Neurosci 8:176184.

Steward O, Ribak CE (1986) Polyribosomes associated with synaptic specializations on axon initial segments: localization of protein-synthetic machincry at inhibitory synapses. J Ncurosci 6:3079-3085.

Steward O, Davis L, Reeves TR, Banker G (1988) Microcompartmentation of the protein synthetic machinery of neurons: polyribosome localization under postsynaptic sites. In: Intrinsic determinants of neuronal function (Lasek RJ, Black MM, eds), pp 525-544. New York: Liss.

Steward O, Pollak A, Rao A (in press) Evidence that protein constituents of postsynaptic membrane specializations are locally synthesized: time course of appearance of recently synthesized proteins in synaptic junctions. J Neurosci Res, in press.

Torre ER, Steward O (1990) A new tissue culture system which enables isolation of living axons and dendrites from their cell bodies: evaluation of local protein synthesis within dendrites. J Cell Biol 111: 493a.

Tucker RP, Garner CC, Matus A (1989) In situ localization of microtubule-associated protein mRNA in the developing and adult rat brain. Neuron 2:1245-1256.

Vazquez D (1974) Inhibitors of protein synthesis. FEBS Lett [Suppl] 1:S63-S84.

Wartiovaara J, Lehtonen E, Nordling S, Saxen L (1972) Do membrane filters prevent cell contacts? Nature 238:407-408.

Wartiovaara J, Lehtonen E, Nordling S, Saxen L (1974) Transfilter induction of kidney tubules: correlation with cytoplasmic penetration into Nucleopore filters. J Embryol Exp Morphol 31:667-682. 